\title{
Optimization of the Thyristor Controlled Phase Shifting Transformer Using PSO Algorithm
}

\author{
Hadi Suyono ${ }^{1}$, Rini Nur Hasanah ${ }^{2}$, Paramita Dwi Putri Pranyata ${ }^{3}$ \\ ${ }^{1,2}$ Department of Electrical Engineering, Faculty of Engineering, Brawijaya University, Indonesia \\ ${ }^{3} \mathrm{PT}$. Infineon Technologies, Indonesia
}

\begin{tabular}{l} 
Article Info \\
\hline Article history: \\
Received Dec 29, 2017 \\
Revised Jul 28, 2018 \\
Accepted Aug 21, 2018
\end{tabular}

\section{Keyword:}

Capacitor Bank

Losses reduction

PSO algorithm

TCPST

TCSC

Voltage profile improvement

\begin{abstract}
The increase of power system demand leads to the change in voltage profile, reliability requirement and system robustness against disturbance. The voltage profile can be improved by providing a source of reactive power through the addition of new power plants, capacitor banks, or implementation of Flexible AC Transmission System (FACTS) devices such as Static VAR Compensator (SVC), Unified Power Flow Control (UPFC), Thyristor Controlled Series Capacitor (TCSC), Thyristor Controlled Phase Shifting Transformer (TCPST), and many others. Determination of optimal location and sizing of device injection is paramount to produce the best improvement of voltage profile and power losses reduction. In this paper, optimization of the combined advantages of TCPST and TCSC has been investigated using Particle Swarm Optimization (PSO) algorithm, being applied to the 30-bus system IEEE standard. The effectiveness of the placement and sizing of TCPST-TCSC combination has been compared to the implementation of capacitor banks. The result showed that the combination of TCPST-TCSC resulted in more effective improvement of system power losses condition than the implementation of capacitor banks. The power losses reduction of $46.47 \%$ and $42.03 \%$ have been obtained using of TCPST-TCSC combination and capacitor banks respectively. The TCPSTTCSC and Capacitor Bank implementations by using PSO algorithm have also been compared with the implementation of Static VAR Compensator (SVC) using Artificial Bee Colony (ABC) Algorithm. The implementation of the TCSC-TCPST compensation with PSO algorithm have gave a better result than using the capacitor bank with PSO algorithm and SVC with the $\mathrm{ABC}$ algorithm.
\end{abstract}

Copyright $(2) 2018$ Institute of Advanced Engineering and Science. All rights reserved.

\section{Corresponding Author:}

Hadi Suyono,

Department of Electrical Engineering, Faculty of Engineering,

Brawijaya University, Malang-Indonesia

Jl. MT. Haryono 167 Malang 65145 Indonesia.

Email: hadis@ub.ac.id

\section{INTRODUCTION}

The increase in electric power demand is in general proportional to the population growth of a country. The load increase usually requires the addition of new power plants, both in terms of the number of units and the generated power capacity. Consequently, further addition and expansion of transmission and distribution systems infrastructure are required. The system becomes more complex and susceptible to interference. Continuity of service must also satisfy technical and economical requirements. Load changes, composition of generating units in operation as well as the changes in network configuration have a great impact on the overall variation of voltage levels and power losses in the system. Voltage profile improvement to fulfill the assigned operation standard of the entire system has some impacts to decrease power losses in 
the system [1]-[2]. Voltage fluctuation can also be controlled through power system compensation. The compensation both in transmission and distribution systems can be performed using either conventional capacitor banks or Flexible Alternating Current Transmission Systems (FACTS) devices [3]-[6]. The FACTS devices implementations include Static VAR Compensator (SVC) [7]-[9], Thyristor Controlled Series Capacitor (TCSC) [10], Thyristor Controlled Phase Shifting Transformer (TCPST) [11], Unified Power Flow Control (UPFC) [12], Dynamic Voltage Restorer (DVR) [13] and many others [14]. Some research results also showed that the use of distributed generation could overcome the voltage profile problem and power losses in distribution system, and also claimed to improve the distribution system performances in terms of power quality [13], reliability [15-16], and stability [17]-[18].

This paper presents the investigation results on the use of combination of two FACTS devices, which are a TCPST and a TCSC, to overcome the voltage profile problem. The TCSC is specifically used to compensate the reactance of the transmission line and commonly used on long transmission line. The main issues explored in the study were the optimal location and sizing for the placement of TCPST-TCSC combination. Comparison to the use of conventional capacitor banks has been performed to justify. There have been many methods proposed to solve the optimization problem, including the heuristic probabilistic and artificial intelligent methods. Genetic Algorithm (AG) method was explored to determine the optimal location of multi-type FACTS [19] and to control the voltage and reactive power [20]-[21]. There were many other artificial intelligent methods such as Artificial Bee Colony algorithm [8], [22], Simulated Annealing [23], Fuzzy EP algorithm [24], and others population algorithm [25], being studied. In this paper, Particle Swarm Optimization (PSO) algorithm is used to solve the optimization problem. However, the PSO algorithm has been used in many applications including the SVC location optimization [26]. PSO algorithm is a method adopting the social behavior of birds when flying together in search of food. Performance of the PSO algorithm to control the voltage profile and power losses have been tested on the 30-bus system IEEE standard data.

\section{POWER SYSTEM COMPENSATION}

\subsection{Thyristor Controlled Phase Shifting Transformer (TCPST)}

TCPST is a device with characteristics similar to conventional Phase Angle Regulators (PAR), being connected in series to network. The main difference lies in the fact that the tap changer is controlled using thyristor to achieve faster operation [14]. The voltage on the primary side is injected thus the phase shifted, and therefore the transmission angle can be controlled. The modeling of power injection at the $\mathrm{i}^{\text {th }}$ and $\mathrm{j}^{\text {th }}$ buses is shown in Figure 1.

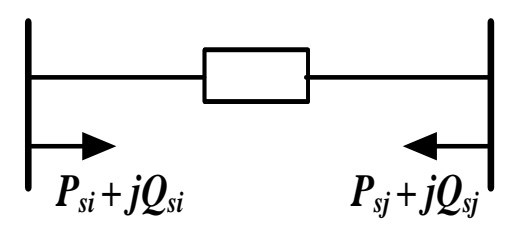

Figure 1. Modeling of TCPST injection

The $P_{\mathrm{si}}, Q_{\mathrm{si}}, P_{\mathrm{sj}}$, and $Q_{\mathrm{sj}}$ parameters can be determined as follows:

$$
\begin{aligned}
P_{\mathrm{Si}} & =\tau b s V_{\mathrm{i}} V_{\mathrm{j}} \sin \left(\theta_{\mathrm{ij}}+\gamma\right) \\
Q_{\mathrm{Si}} & =\tau^{2} b s V_{\mathrm{i}}^{2}-\tau b s V_{\mathrm{i}} V_{\mathrm{j}} \cos \left(\theta_{\mathrm{ij}}+\gamma\right) \\
P_{\mathrm{Sj}} & =-\tau b s V_{\mathrm{i}} V_{\mathrm{j}} \sin \left(\theta_{\mathrm{ij}}+\gamma\right) \\
Q_{\mathrm{Sj}} & =-\tau b s V_{\mathrm{i}} V_{\mathrm{j}} \cos \left(\theta_{\mathrm{ij}}+\gamma\right)
\end{aligned}
$$

where $\tau=\frac{\left|V_{\mathrm{S}}\right|}{\left|V_{\mathrm{i}}\right|}, b \mathrm{~s}=\frac{1}{X_{\mathrm{s}}}$, and $\gamma$ is the angle to be controlled by TCPST. The voltage phase-angle which can be controlled by TCPST is in the range between $-5^{\circ}$ and $5^{\circ}$. Figure 2 indicates the modeling of TCPST in the transmission line [14]. 


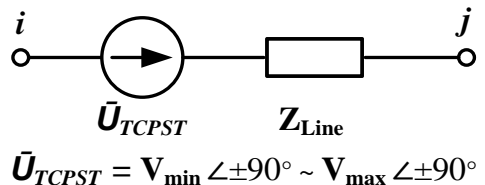

Figure 2. The TCSC model in transmission line

\subsection{Thyristor Controlled Series Capacitor (TCSC)}

TCSC is one type of FACTS devices which combines a Thyristor Controlled Reactor (TCR) with capacitor [14]. The TCR consists of inductor being connected in series with thyristor. TCSC is capable to adjust reactance of transmission line by controlling the thyristor firing-angle. Figure 3 represents a simple modeling of series TCSC. To avoid over compensation, the injection of TCSC is set on $20 \%$ inductive $\left(0.2 X_{\text {line }}\right)$ up to $70 \%$ capacitive $\left(-0.7 X_{\text {line }}\right)$ of the line reactance [28], such that:

$$
r_{\mathrm{TCSCmin}}=-0.7 \text { and } r_{\mathrm{TCSCmax}}=0.2
$$

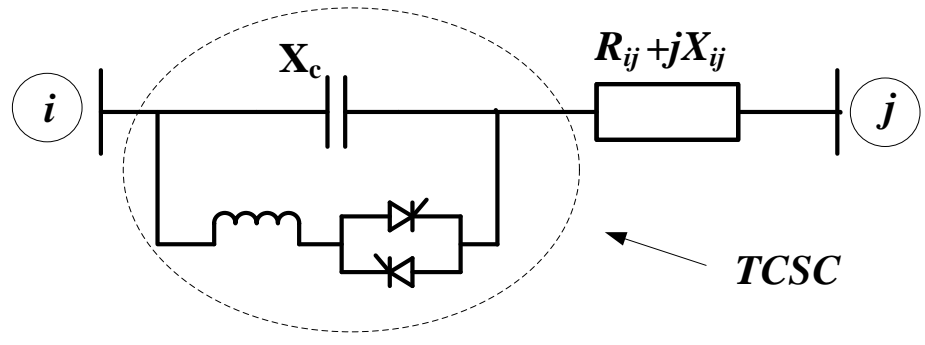

Figure 3. The modeling of TCSC

The TCSC modeling which enables the reactance control of the transmission line is shown in Figure 4 [28]. The relationship between the TCSC rating to the transmission line reactance is expressed as follows:

$$
\begin{aligned}
& X_{\text {total }}=X_{\text {line }}+X_{\mathrm{TCSC}} \\
& X_{\mathrm{TCSC}}=r_{\mathrm{TCSC}} \times X_{\text {line }}
\end{aligned}
$$

where $X_{\text {line }}$ is the line reactance and $r_{\mathrm{TCSC}}$ is the compensation rating of TCSC.

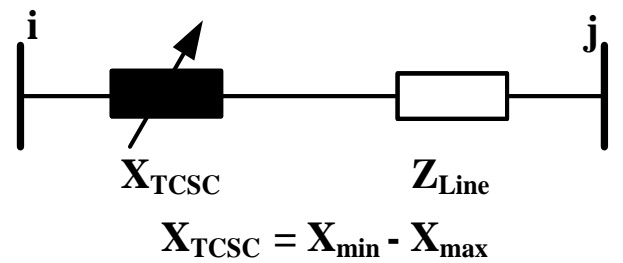

Figure 4. The TCSC modeling in the transmission system

\section{PARTICLE SWARM OPTIMIZATION (PSO)}

Particle Swarm Optimization (PSO) algorithm is an optimization technique within a problem space which adopts the behavior of birds or fishes in finding food. In general, the PSO algorithm process to solve an optimization problem can be represented using a flowchart shown in Figure 5. The steps to find the optimum value using the PSO algorithm can be described as follows:

1. Initialize the particle positions randomly within a problem space. 

Particle_position $=$ Minimum_Limit $+($ Maximum_Limit - Minimum_Limit $) \times$
rand $(1$, Particle_Number $)$

2. Initialize the velocity of each particle:

$$
\begin{aligned}
& V_{\max }=\frac{(\text { Max_limit }- \text { Minimum_limit })}{N} \\
& \text { Particle_Velocity }=\left(V_{\max }-V_{\min }\right) \times \text { rand }(1, \text { Particle_Number })+V_{\min }
\end{aligned}
$$

3. Evaluate the objective function of each particle.

4. Calculate the best position/location $\left(P_{\text {best }}\right)$ and the best global position $\left(G_{\text {best }}\right)$.

5. Update velocity and position of a particle, as shown in Equation (13) and (14). In this stage, the acceleration coefficient $c_{1}$ and $c_{2}$ being used are generally within the values of 0 to 4 . A weight function (w), in the range of 0.4 to 0.9 , is also used to control the exploration of global and local particles. The improvement of the weight function can be done using Equation (11).

6.

$$
\begin{aligned}
& w(\mathrm{t})=\left(w_{\text {max }}-w_{\text {min }}\right) \times\left(\frac{\text { iter }_{\text {max }}-\text { iter }(\mathrm{t})}{\text { iter }_{\max }}\right)+w_{\text {min }} \\
& V_{\text {id }}(\mathrm{t}+1)=w(\mathrm{t}) \times V_{\text {id }}(\mathrm{t})+c_{1} \times T_{1 \mathrm{~d}}(\mathrm{t}) \times\left(P_{\text {best id }}(\mathrm{t})-X_{\text {id }}(\mathrm{t})\right)+c_{2} \times T_{2 \mathrm{~d}}(\mathrm{t}) \times\left(G_{\text {bestd }}(\mathrm{t})-\right. \\
& \left.X_{\text {id }}(\mathrm{t})\right) \\
& X_{\text {id }}(\mathrm{t}+1)=X_{\text {id }}(\mathrm{t})+V_{\text {id }}(\mathrm{t})
\end{aligned}
$$

where $t$ is the iteration step, $V_{i d}(\mathrm{t})$ is the current velocity of the particle $i$ in the dimension $d$ at iteration step $t, V_{i d}(\mathrm{t}+1)$ is the velocity of the particle $i$ in the dimension $d$ at iteration step $t+1, X_{I D}(\mathrm{t})$ is the current position of particle $i$ in the dimension $d$ at the iteration step $t, X_{I D}(\mathrm{t}+1)$ is the position of particle $i$ in dimension $d$ at iteration $t+1, c_{1}$ is the acceleration constant 1 (cognitive constant), $c_{2}$ is the acceleration constant 2 (social constant), $T_{I D}(\mathrm{t})$ and $T_{2 \mathrm{D}}(\mathrm{t})$ are random numbers uniformly distributed between 0 and $1, P_{\text {bestid }}(\mathrm{t})$ is the local best position of particle $i$ in dimension $d$ at iteration $t$, and $G_{\text {bestid }}(\mathrm{t})$ is the local best position of the global at iteration $t$.

7. Evaluate the objective function value on the next iteration.

8. Determine the final of $P_{\text {best }}$ and $G_{\text {best }}$

9. Evaluate whether the solution is optimal, if a convergence has been achieved then it comes to end, otherwise going back to step 3 .

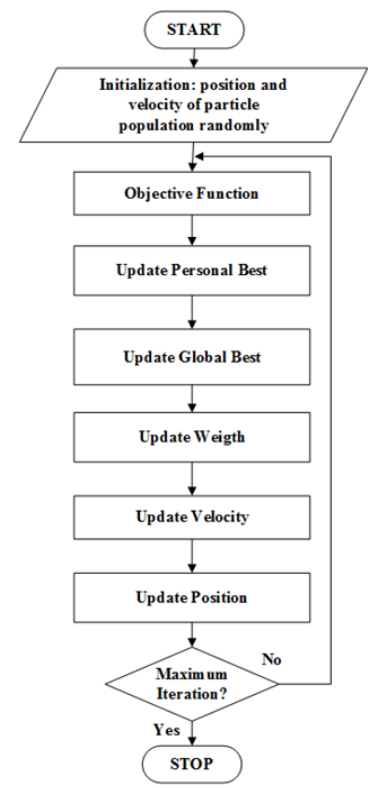

Figure 5. Steps to follow using the PSO algorithm 
The flowchart of the PSO algorithm implementation is shown in Figure 6, whereas the control parameters used is given Table 1 .

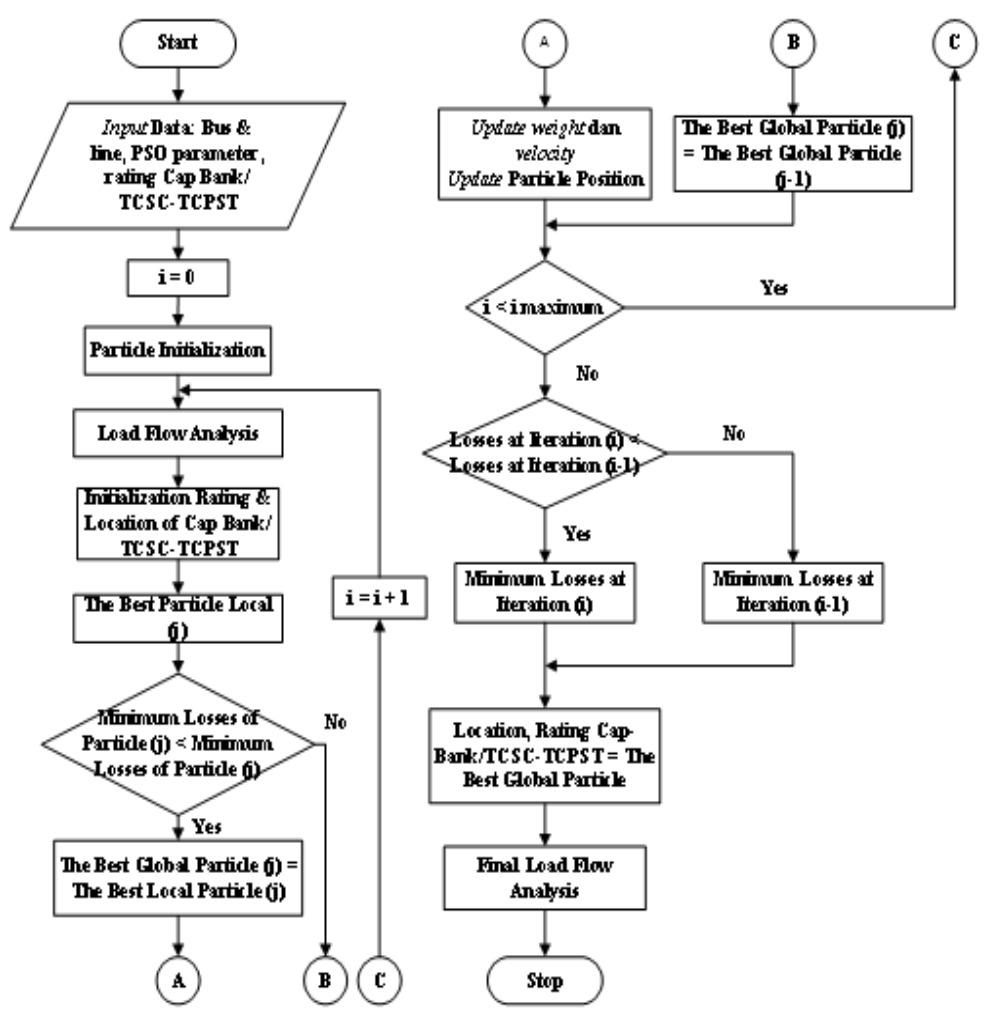

Figure 6. PSO solution

Table 1. The PSO control parameters

\begin{tabular}{cc}
\hline Parameter & Value \\
\hline Number of Particle & 50 \\
Maximum Iteration & 20 \\
Number of Variable & 3 \\
$c_{1}$ and $c_{2}$ & 4 \\
weight $(w)$ & 0,4 \\
$r_{\text {TCSC }}$ maximum & $0,2 X_{\text {line }}$ \\
$r_{\text {TCSC }}$ minimum & $-0,7 X_{\text {line }}$ \\
$\delta_{\text {TCPS }}$ maximum & $5^{\circ}$ \\
$\delta_{\text {TCPST }}$ minimum & $-5^{\circ}$ \\
Objective Function & Min F $=$ min $P_{\text {loss }}$ \\
\hline
\end{tabular}

\section{RESULTS AND DISCUSSION}

In this study, the proposed solution has been simulated and tested using 30-bus system IEEE standard data. The results of the power flow analysis have been obtained from some scenarios including the conditions without any injection of compensation, the condition with injection of optimum capacitor bank compensation, and the condition with injection of optimum TCPST-TCSC compensation. The PSO algorithm implementation to determine the optimum location and sizing of the compensation using the TCPST-TCSC combination has been compared to that using capacitor bank. In addition, the PSO algorithm performance has also been compared with the implementation of Artificial Bee Colony (ABC) Algorithm [8].

\subsection{IEEE 30 Bus System Data}

The performance of the PSO algorithm has been tested using the 30-bus system IEEE standard data as follows: Bus Number: 30, Slack bus: Bus no\#1, Generator: Bus no\# 2, 5, 8, 11, and 13, Total demand: 201.43 MW and 137.80 MVAR. The PSO algorithm will determine the best location and sizing of the reactive power required in the system by performing the load flow analysis for each iteration. There are four 
(4) cases of the system that will be performed to show the performance of the PSO algorithm and the implemented of the compensator devices i.e.:

- Case\#1: without any injection of compensation,

- Case\#2: with injection of capacitor bank compensation

- Case\#3: with injection TCPST-TCSC compensation

- Case\#4: with injection SVC compensation by using another optimization method i.e. Artificial Bee Colony (ABC) Algorithm [8].

For Case\#2 and \#3, the load flow analyses have been performed after the determination of optimum location and capacity of reactive power compensation required in the system using the PSO algorithm. In addition, the PSO Algorithm is also compared with ABC algorithm as given in Case\#4.

\subsection{Results of Case\#1: without any injection of compensation}

In this analysis, the 30-bus IEEE system has been tested under the condition without any compensating device. Based on the load flow analysis, the power flow as well as power losses on each branch, and the voltage on each system bus could be determined. Newton Raphson algorithm has been adopted to solve the load flow problem based on the following parameters: base power=100 MVA, accuracy $=0.00001$, and maximum iteration number $=20$. The results of load flow analysis for this case is shown in Table 2.

Based on Table 2, total active and reactive power generated were around 205.489 MW and 118.401 MVAR respectively. In addition, the total active and reactive power losses in the system were approximately 4.061 MW and -19.399 MVAR. There were three buses experiencing under voltage problem, being lower than the allowable minimum voltage, i.e. 0.95 p.u. The buses with voltage level beyond the limits occurred on bus\# 18, bus\#19, and bus\#20. The percentage of the active power losses is about $2.02 \%$ with respect to the active power load.

Table 2. Load flow results Case\#1

\begin{tabular}{|c|c|c|c|c|c|c|}
\hline \multirow[b]{2}{*}{ Bus\# } & \multicolumn{2}{|c|}{ Voltage } & \multicolumn{2}{|c|}{ Load } & \multicolumn{2}{|c|}{ Generation } \\
\hline & $|\mathrm{V}|(\mathrm{pu})$ & $\square$ & $\mathrm{P}(\mathrm{MW})$ & $\begin{array}{l}\text { Q } \\
\text { (MVAR) }\end{array}$ & $\mathrm{P}(\mathrm{MW})$ & $\begin{array}{c}\mathrm{Q} \\
\text { (MVAR) }\end{array}$ \\
\hline 1 & 1 & 0 & 0 & 0 & 24.819 & -1.742 \\
\hline 2 & 1 & -0.334 & 21.7 & 12.7 & 60.97 & 30.371 \\
\hline 3 & 0.983 & -1.353 & 2.4 & 1.2 & 0 & 0 \\
\hline 4 & 0.979 & -1.597 & 7.6 & 1.6 & 0 & 0 \\
\hline 5 & 0.983 & -1.767 & 0 & 0 & 0 & 0 \\
\hline 6 & 0.971 & -2.05 & 0 & 0 & 0 & 0 \\
\hline 7 & 0.967 & -2.494 & 22.8 & 10.9 & 0 & 0 \\
\hline 8 & 0.958 & -2.531 & 30 & 30 & 0 & 0 \\
\hline 9 & 0.963 & -2.531 & 0 & 0 & 0 & 0 \\
\hline 10 & 0.96 & -2.789 & 5.9 & 2 & 0 & 0 \\
\hline 11 & 0.963 & -2.531 & 0 & 0 & 0 & 0 \\
\hline 12 & 0.975 & -1.346 & 11.2 & 7.5 & 0 & 0 \\
\hline 13 & 1 & 1.7 & 0 & 0 & 37 & 18.855 \\
\hline 14 & 0.962 & -2.055 & 6.2 & 1.6 & 0 & 0 \\
\hline 15 & 0.962 & -1.898 & 8.2 & 2.5 & 0 & 0 \\
\hline 16 & 0.96 & -2.263 & 3.5 & 1.8 & 0 & 0 \\
\hline 17 & 0.954 & -2.882 & 9 & 5.8 & 0 & 0 \\
\hline 18 & 0.914 & -2.133 & 3.2 & 0.9 & 0 & 0 \\
\hline 19 & 0.889 & -2.027 & 9.5 & 34 & 0 & 0 \\
\hline 20 & 0.905 & -2.33 & 2.2 & 0.7 & 0 & 0 \\
\hline 21 & 0.971 & -2.877 & 19.669 & 11.2 & 0 & 0 \\
\hline 22 & 0.98 & -2.708 & 0 & 0 & 31.59 & 36.954 \\
\hline 23 & 1 & -1.603 & 3.2 & 1.6 & 22.2 & 20.463 \\
\hline 24 & 0.975 & -2.752 & 15 & 6.7 & 0 & 0 \\
\hline 25 & 0.984 & -2.015 & 1 & 0 & 0 & 0 \\
\hline 26 & 0.966 & -2.464 & 3.5 & 2.3 & 0 & 0 \\
\hline 27 & 1 & -1.154 & 0 & 0 & 28.91 & 13.5 \\
\hline 28 & 0.973 & -2.122 & 0 & 0 & 0 & 0 \\
\hline 29 & 0.976 & -2.808 & 3.659 & 0.9 & 0 & 0 \\
\hline 30 & 0.964 & -3.803 & 12 & 1.9 & 0 & 0 \\
\hline \multicolumn{3}{|c|}{ Total } & 201.428 & 137.8 & 205.489 & 118.401 \\
\hline \multicolumn{3}{|c|}{ Total Losses } & 4.061 & MW & -19.399 & MVAR \\
\hline \multicolumn{3}{|c|}{$\%$ of Losses } & $2.02 \%$ & MW & $-16.4 \%$ & MVAR \\
\hline
\end{tabular}




\subsection{Results of Case\#2: with injection of capacitor bank compensation}

IEEE standard system has been tested for the condition with the placement of capacitor bank. The number of capacitor banks required in the system was 3 locations with capacity values between 0 up to 50 MVAR. The optimum location and capacity of capacitor bank used are shown in Table 3. From the table it can be seen that the resulted location and capacity of capacitor bank after optimization using the PSO algorithm were 12.5433 MVAR (0.2502 p.u.) located at bus\#17, 25.5432 MVAR (0.5105 p.u.) located at bus\#7, and 28.2801 MVAR (0.5664 p.u.) located at bus\#31.

Table 3. Capacitor bank optimization results for Case\#2 using the PSO algorithm

\begin{tabular}{cccc}
\hline Compensation & Bus No\# Location & Rating (p.u.) & Rating (MVAR) \\
\hline Capacitor Bank & 17 & 0.2502 & 12.5433 \\
Capacitor Bank & 7 & 0.5105 & 25.5432 \\
Capacitor Bank & 31 & 0.5664 & 28.2801 \\
\hline
\end{tabular}

Table 4 shows the simulation result of the system after the optimum placement of the capacitor banks with the minimum power losses. It can be seen that the total power generated were around $213.83 \mathrm{MW}$ for active power and 149.91 MVAR for reactive power. The total active and reactive power losses for Case\#2 were 9.901 MW and 16.009 MVAR respectively. There is no voltage violation for the Case\#2 since all of bus voltage values were in the range of 0.95 p.u. to 1.05 p.u. The voltage profile for each bus is depicted in Figure 8 . The voltage level of buses which experienced under voltage condition in Case \# 1 has been rising to meet the allowable voltage level.

Table 4. Load flow results for Case\#2

\begin{tabular}{|c|c|c|c|c|c|c|}
\hline \multirow{2}{*}{ Bus\# } & \multicolumn{2}{|c|}{ Voltage } & \multicolumn{2}{|c|}{ Load } & \multicolumn{2}{|c|}{ Generation } \\
\hline & $|\mathrm{V}|(\mathrm{pu})$ & $\alpha$ & $\mathrm{P}(\mathrm{MW})$ & Q (MVAR) & $\mathrm{P}(\mathrm{MW})$ & $\mathrm{Q}$ (MVAR) \\
\hline 1 & 1 & 0 & 0 & 0 & 23.112 & -10.156 \\
\hline 2 & 1 & -0.288 & 21.7 & 12.7 & 60.97 & 6.641 \\
\hline 3 & 0.998 & -1.52 & 2.4 & 1.2 & 0 & 0 \\
\hline 4 & 0.997 & -1.813 & 7.6 & 1.6 & 0 & 0 \\
\hline 5 & 0.991 & -1.796 & 0 & 0 & 0 & 0 \\
\hline 6 & 0.987 & -2.224 & 0 & 0 & 0 & 0 \\
\hline 7 & 0.98 & -2.602 & 22.8 & 10.9 & 0 & 0 \\
\hline 8 & 0.974 & -2.68 & 30 & 30 & 0 & 0 \\
\hline 9 & 0.997 & -2.743 & 0 & 0 & 0 & 0 \\
\hline 10 & 0.989 & -3.018 & 5.9 & 2 & 0 & 0 \\
\hline 11 & 0.997 & -2.743 & 0 & 0 & 0 & 0 \\
\hline 12 & 0.989 & -1.373 & 11.2 & 7.5 & 0 & 0 \\
\hline 13 & 1 & 1.628 & 0 & 0 & 37 & 8.645 \\
\hline 14 & 0.979 & -2.077 & 6.2 & 1.6 & 0 & 0 \\
\hline 15 & 0.982 & -2.015 & 8.2 & 2.5 & 0 & 0 \\
\hline 16 & 0.981 & -2.401 & 3.5 & 1.8 & 0 & 0 \\
\hline 17 & 0.981 & -3.059 & 9 & 5.8 & 0 & 0 \\
\hline 18 & 0.969 & -3.08 & 3.2 & 0.9 & 0 & 0 \\
\hline 19 & 0.965 & -3.503 & 9.5 & 34 & 0 & 0 \\
\hline 20 & 0.97 & -3.45 & 2.2 & 0.7 & 0 & 0 \\
\hline 21 & 0.994 & -2.944 & 19.669 & 11.2 & 0 & 0 \\
\hline 22 & 1 & -2.73 & 0 & 0 & 31.59 & 26.998 \\
\hline 23 & 1 & -1.134 & 3.2 & 1.6 & 22.2 & 6.703 \\
\hline 24 & 0.985 & -2.548 & 15 & 6.7 & 0 & 0 \\
\hline 25 & 0.988 & -1.87 & 1 & 0 & 0 & 0 \\
\hline 26 & 0.97 & -2.315 & 3.5 & 2.3 & 0 & 0 \\
\hline 27 & 1 & -1.051 & 0 & 0 & 28.91 & 8.488 \\
\hline 28 & 0.988 & -2.236 & 0 & 0 & 0 & 0 \\
\hline 29 & 0.976 & -2.705 & 3.659 & 0.9 & 0 & 0 \\
\hline 30 & 0.964 & -3.7 & 12 & 1.9 & 0 & 0 \\
\hline \multicolumn{3}{|c|}{ Total } & 201.428 & 137.8 & 203.782 & 47.319 \\
\hline \multicolumn{3}{|c|}{ Total Losses } & 2.354 & MW & -24.114 & MVAR \\
\hline \multicolumn{3}{|c|}{$\%$ of Losses } & $1.17 \%$ & & $-17.5 \%$ & \\
\hline
\end{tabular}

The process in achieving the minimum power losses using the PSO algorithm is shown in Figure 7. The minimum power loss on each iteration as the objective function has been recorded. It is only after reaching the convergence criteria that the PSO algorithm steps could be ended. The maximum iterations 
performed for the test were 20 iterations. Based on the figure, it also showed that the minimum active power losses can be reached on the $5^{\text {th }}$ iteration with the value of $2.354 \mathrm{MW}$.

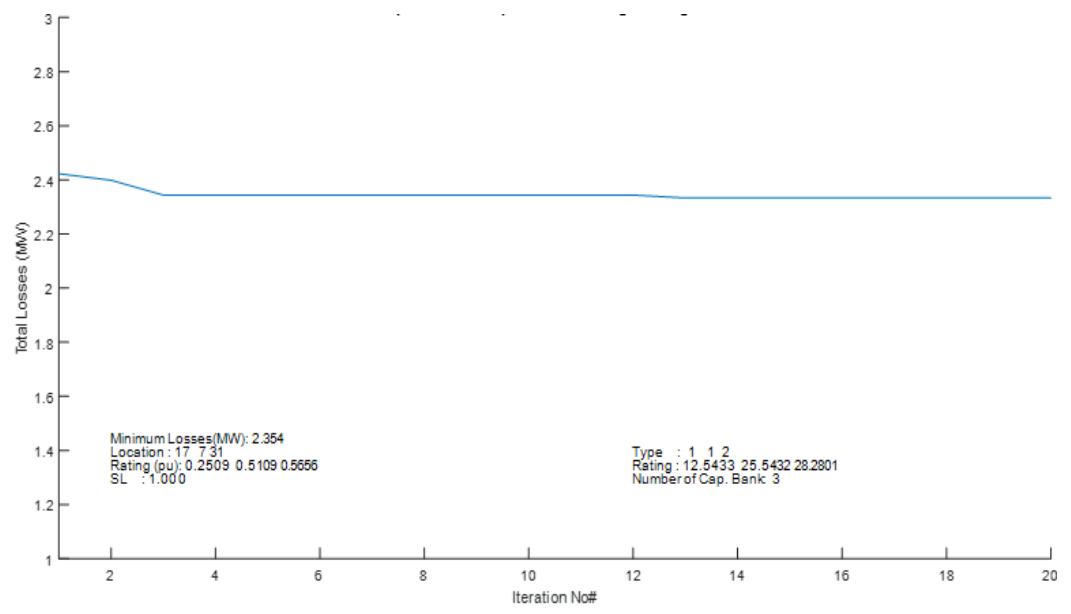

Figure 7. The convergence criteria for Case\#2

\subsection{Result of Case\#3: with injection TCSC-TCPST compensation}

In this part, the standard IEEE 30-bus system has been tested in a condition with TCSC-TCPST being implemented in the system. Based on the results, the optimum location and size of the TCSC-TCPST is are shown in Table 5. The optimum place of TCSC was on the line\#15 which was connected to bus\#27 and bus\#29 with a rating of $-0,5535 X_{\text {line }}$ and line\#31 which was connected to bus\#27 and bus\#30 with the rating of $-0,5343 X$ line. In addition, the TCPST has also been implemented in the line\#26 which was connected to bus\#10 and bus\#20 with the injected phase-angle of $-2.6839^{\circ}$.

The simulation results of the system after the placement of TCSC and TCPST for the most minimum power loss is shown in Table 6 . It can be seen that the total power generated by the generator was equal to 203.602 MW and 40.891 MVAR for active power and reactive power respectively. The total active and reactive power losses for Case\#3 were 2.174 MW and -25.041 MVAR respectively. There was no voltage violation for the Case\#3 since the voltage of all buses were in the range of 0.95 p.u. -1.05 p.u. The percentage of the power losses is about $1.07 \%$ with respect to the active power load.

The process in achieving the minimum power losses for Case\#3 with TCSC-TCPST compensation using the PSO algorithm is given in Figure 8 . The minimum active power losses could be reached on the $14^{\text {th }}$ iteration with the value of $2.174 \mathrm{MW}$.

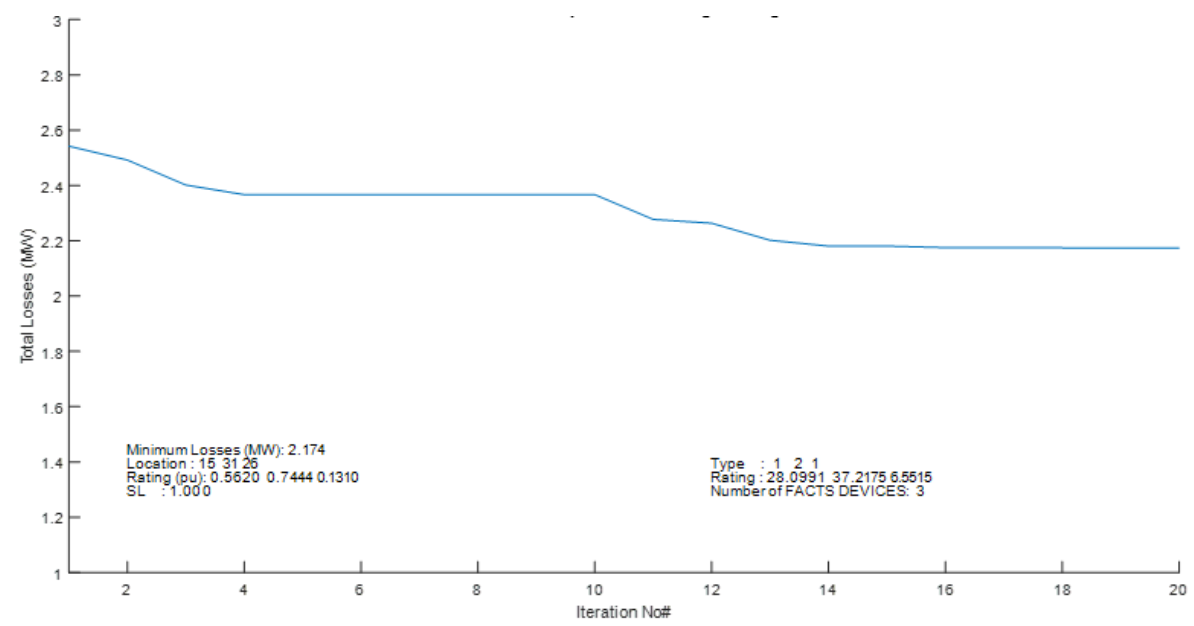

Figure 8. The convergence criteria for Case\#3 
Table 5. TCSC \& TCPST optimization results using the PSO algorithm for Case\#3

\begin{tabular}{ccccc}
\hline Compensation & Location (Line) & From Bus & To Bus & Rating \\
\hline TCSC & 15 & 27 & 29 & $-0,5535 \mathrm{X}_{\text {line }}$ \\
TCSC & 31 & 27 & 30 & $-0,5343 \mathrm{X}_{\text {line }}$ \\
TCPST & 26 & 10 & 20 & $-2,6839^{\circ}$ \\
\hline
\end{tabular}

Table 6. Load flow results for Case\#3

\begin{tabular}{|c|c|c|c|c|c|c|}
\hline \multirow{2}{*}{ Bus\# } & \multicolumn{2}{|c|}{ Voltage } & \multicolumn{2}{|c|}{ Load } & \multicolumn{2}{|c|}{ Generation } \\
\hline & $|\mathrm{V}|(\mathrm{pu})$ & $\alpha$ & $\mathrm{P}(\mathrm{MW})$ & Q (MVAR) & $\mathrm{P}(\mathrm{MW})$ & $\mathrm{Q}$ (MVAR) \\
\hline 1 & 1 & 0 & 0 & 0 & 22.932 & -8.16 \\
\hline 2 & 1 & -0.284 & 21.7 & 12.7 & 60.97 & 5.876 \\
\hline 3 & 0.995 & -1.467 & 2.4 & 1.2 & 0 & 0 \\
\hline 4 & 0.993 & -1.746 & 7.6 & 1.6 & 0 & 0 \\
\hline 5 & 0.993 & -1.81 & 0 & 0 & 0 & 0 \\
\hline 6 & 0.991 & -2.269 & 0 & 0 & 0 & 0 \\
\hline 7 & 0.983 & -2.633 & 22.8 & 10.9 & 0 & 0 \\
\hline 8 & 0.988 & -2.887 & 30 & 30 & 0 & 0 \\
\hline 9 & 0.99 & -2.753 & 0 & 0 & 0 & 0 \\
\hline 10 & 0.989 & -3.009 & 5.9 & 2 & 0 & 0 \\
\hline 11 & 0.99 & -2.753 & 0 & 0 & 0 & 0 \\
\hline 12 & 0.993 & -1.393 & 11.2 & 7.5 & 0 & 0 \\
\hline 13 & 1 & 1.597 & 0 & 0 & 37 & 5.978 \\
\hline 14 & 0.993 & -2.445 & 6.2 & 1.6 & 0 & 0 \\
\hline 15 & 0.989 & -2.109 & 8.2 & 2.5 & 0 & 0 \\
\hline 16 & 0.983 & -2.398 & 3.5 & 1.8 & 0 & 0 \\
\hline 17 & 0.982 & -3.054 & 9 & 5.8 & 0 & 0 \\
\hline 18 & 0.983 & -3.366 & 3.2 & 0.9 & 0 & 0 \\
\hline 19 & 0.983 & -3.904 & 9.5 & 34 & 0 & 0 \\
\hline 20 & 0.983 & -3.739 & 2.2 & 0.7 & 0 & 0 \\
\hline 21 & 0.994 & -2.93 & 19.669 & 11.2 & 0 & 0 \\
\hline 22 & 1 & -2.714 & 0 & 0 & 31.59 & 26.712 \\
\hline 23 & 1 & -1.068 & 3.2 & 1.6 & 22.2 & 3.302 \\
\hline 24 & 0.985 & -2.524 & 15 & 6.7 & 0 & 0 \\
\hline 25 & 0.988 & -1.884 & 1 & 0 & 0 & 0 \\
\hline 26 & 0.97 & -2.329 & 3.5 & 2.3 & 0 & 0 \\
\hline 27 & 1 & -1.088 & 0 & 0 & 28.91 & 7.183 \\
\hline 28 & 0.993 & -2.303 & 0 & 0 & 0 & 0 \\
\hline 29 & 0.976 & -2.743 & 3.659 & 0.9 & 0 & 0 \\
\hline 30 & 0.964 & -3.738 & 12 & 1.9 & 0 & 0 \\
\hline & Total & & 201.428 & 137.8 & 203.602 & 40.891 \\
\hline & Total Losses & & 2.174 & MW & -25.041 & MVAR \\
\hline & $\%$ of Losses & & $1.07 \%$ & & $-18.2 \%$ & \\
\hline
\end{tabular}

\subsection{Result of Case\#4: with injection SVC using Artificial Bee Colony (ABC) Algorithm [8]}

To show the performance of the PSO algorithm, the comparison with Artificial Bee Colony (ABC) Algorithm [8] result has been made. The same simulation using IEEE 30-bus system as a base-case data have been made and compared in terms of voltage profile and the best active power loss reached. Based on the $\mathrm{ABC}$ algorithm result shows that the number of SVCs required in the system was two (2) locations with capacity values 36.996 MVAR at bus\#5 and 36.971 MVAR at bus\#19 respectively.

The simulation results of the system after the placement of SVC for the most minimum power loss is shown in Table 7. It can be seen that the total power generated by the generator was equal to $204.21 \mathrm{MW}$ and 48.40 MVAR for active power and reactive power. The total active and reactive power losses obtained for this case were 2.7927 MW and -15.2076 MVAR respectively. There was no voltage violation in this case since the voltage of all buses were in the acceptable range. The percentage of the power losses is about $1.37 \%$ with respect to the active power load.

Table 7. Load flow results for Case\#4: with injection SVC using ABC Algorithm [8]

\begin{tabular}{ccccccc}
\hline \multirow{2}{*}{ Bus\# } & \multicolumn{2}{c}{ Voltage } & \multicolumn{2}{c}{ Load } & \multicolumn{2}{c}{ Generation } \\
\cline { 2 - 7 } & $|\mathrm{V}|(\mathrm{pu})$ & $\alpha$ & $\mathrm{P}(\mathrm{MW})$ & $\mathrm{Q}(\mathrm{MVAR})$ & $\mathrm{P}(\mathrm{MW})$ & $\mathrm{Q}(\mathrm{MVAR})$ \\
\hline 1 & 1 & 0 & 0 & 0.00 & 23.54 & -5.64 \\
2 & 1 & -0.369 & 21.7 & 12.70 & 60.97 & 1.60 \\
3 & 0.9883 & -1.535 & 2.4 & 1.20 & 0.00 & 0.00 \\
4 & 0.986 & -1.786 & 7.6 & 1.60 & 0.00 & 0.00
\end{tabular}


Table 7. Load flow results for Case\#4: with injection SVC using ABC Algorithm [8]

\begin{tabular}{ccccccc}
\hline \multirow{2}{*}{ Bus\# } & \multicolumn{2}{c}{ Voltage } & \multicolumn{2}{c}{ Load } & \multicolumn{2}{c}{ Generation } \\
\cline { 2 - 7 } & $|\mathrm{V}|(\mathrm{pu})$ & $\alpha$ & $\mathrm{P}(\mathrm{MW})$ & $\mathrm{Q}(\mathrm{MVAR})$ & $\mathrm{P}(\mathrm{MW})$ & $\mathrm{Q}(\mathrm{MVAR})$ \\
\hline 5 & 1.0223 & -2.472 & 0 & 0.00 & 0.00 & 0.00 \\
6 & 0.9815 & -2.246 & 0 & 0.00 & 0.00 & 0.00 \\
7 & 0.9885 & -2.846 & 22.8 & 10.90 & 0.00 & 0.00 \\
8 & 0.9694 & -2.709 & 30 & 30.00 & 0.00 & 0.00 \\
9 & 0.979 & -2.825 & 0 & 0.00 & 0.00 & 0.00 \\
10 & 0.9776 & -3.129 & 5.9 & 2.00 & 0.00 & 0.00 \\
11 & 0.979 & -2.825 & 0 & 0.00 & 0.00 & 0.00 \\
12 & 0.986 & -1.415 & 11.2 & 7.50 & 0.00 & 0.00 \\
13 & 1 & 1.5966 & 0 & 0.00 & 37.00 & 10.95 \\
14 & 0.9775 & -2.14 & 6.2 & 1.60 & 0.00 & 0.00 \\
15 & 0.9815 & -2.106 & 8.2 & 2.50 & 0.00 & 0.00 \\
16 & 0.9745 & -2.472 & 3.5 & 1.80 & 0.00 & 0.00 \\
17 & 0.9708 & -3.181 & 9 & 5.80 & 0.00 & 0.00 \\
18 & 0.9733 & -3.426 & 3.2 & 0.90 & 0.00 & 0.00 \\
19 & 0.9727 & -3.99 & 9.5 & 34.00 & 0.00 & 0.00 \\
20 & 0.9727 & -3.834 & 2.2 & 0.70 & 0.00 & 0.00 \\
21 & 0.9746 & -3.507 & 19.669 & 11.20 & 0.00 & 0.00 \\
22 & 1 & -2.072 & 0 & 0.00 & 31.59 & 24.64 \\
23 & 1 & -0.962 & 3.2 & 1.60 & 22.20 & 6.94 \\
24 & 0.9848 & -2.159 & 15 & 6.70 & 0.00 & 0.00 \\
25 & 0.988 & -1.648 & 1 & 0.00 & 0.00 & 0.00 \\
26 & 0.97 & -2.1 & 3.5 & 2.30 & 0.00 & 0.00 \\
27 & 1 & -0.928 & 0 & 0.00 & 28.91 & 9.92 \\
28 & 0.9831 & -2.291 & 0 & 0.00 & 0.00 & 0.00 \\
29 & 0.9762 & -2.531 & 3.659 & 0.90 & 0.00 & 0.00 \\
30 & 0.9637 & -3.538 & 12 & 1.90 & 0.00 & 0.00 \\
& Total & & 201.428 & 137.80 & 204.21 & 48.40 \\
& Total Losses & & 2.7927 & MW & -15.2076 & MVAR \\
& $\%$ of Losses & & $1.37 \%$ & & $-31.42 \%$ & \\
\hline & & & & & &
\end{tabular}

\subsection{Comparison results between cases}

The results of system simulation on IEEE 30-bus system with four cases have been compared in terms of voltage profile and the best active power loss reached for each case by using the PSO algorithm and ABC algorithm [8]. Figure 8 shows the voltage profiles comparison. The worst voltage profile has been experienced in Case\#1 where the availability of the reactive power was very limited depending on the generating unit. There are three buses were below the allowable minimum voltage of 0.95 p.u.

However, the supply of the reactive power depended on the output of the active power loading for each unit. On the other hand, the voltage profiles have been improved in Case\#2 and Case\#3 by using PSO algorithm and Case\#4 by using ABC algorithm, since the reactive power sources have been implemented to support the deficiency of the reactive power. All of the buses voltage was above 0.95 p.u., since the reactive power compensations required in the system were satisfied using capacitor bank for Case\#2, TCSC-TCPST for Case\#3, and SVC for Case\#4. The Case\#3 showed a better voltage profile compared to the other cases.

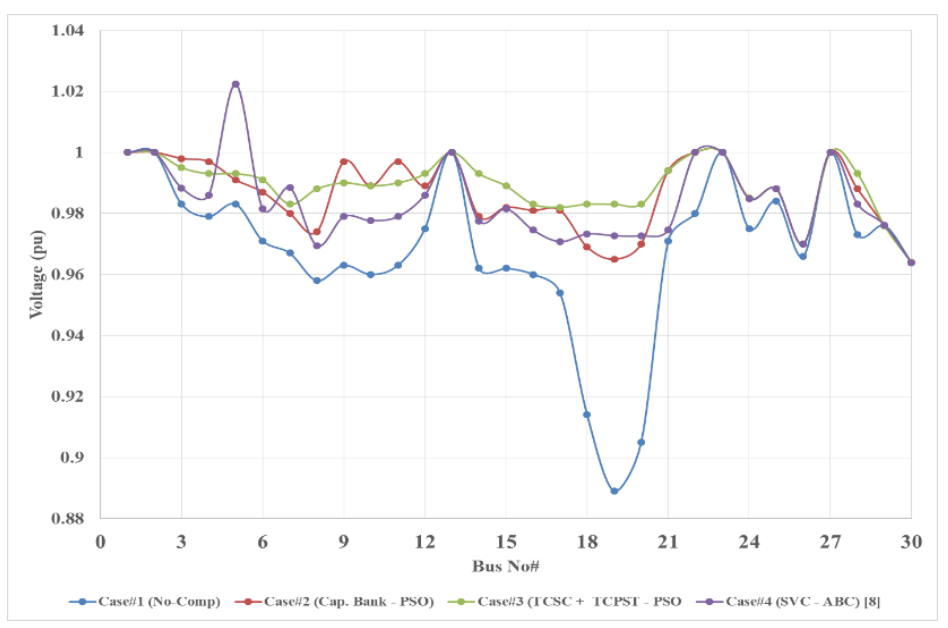

Figure 8. Voltage profile comparison for each case 
Table 7. Comparison of active power losses between cases

\begin{tabular}{|c|c|c|c|c|}
\hline Simulation & $\begin{array}{l}\text { Case\#1 (No- } \\
\text { Comp) }\end{array}$ & $\begin{array}{l}\text { Case\#2 (Cap. } \\
\text { Bank - PSO) }\end{array}$ & $\begin{array}{l}\text { Case\#3 }(\mathrm{TCSC}+ \\
\text { TCPST }- \text { PSO) }\end{array}$ & $\begin{array}{l}\text { Case\#4 (SVC - } \\
\text { ABC) }[8]\end{array}$ \\
\hline Active Power Losses (MW) (a) & 4.061 & 2.354 & 2.174 & 2.793 \\
\hline$\%$ of (a) respect to active power load & $2.02 \%$ & $1.17 \%$ & $1.07 \%$ & $1.37 \%$ \\
\hline $\begin{array}{c}\text { Active power losses improvement respect to } \\
\text { Case\#1 (MW) }\end{array}$ & 0.000 & 1.707 & 1.887 & 1.268 \\
\hline $\begin{array}{c}\text { Percentage of active power losses improvement } \\
\text { respect to Case\#1 }(\%)\end{array}$ & $0.00 \%$ & $42.03 \%$ & $46.47 \%$ & $31.23 \%$ \\
\hline
\end{tabular}

Table 7 shows the comparison of active power losses for the four cases. The percentage of active power losses referred to the total active power load is given in the table. The implementation of the capacitor banks and the TCSC-TCPST combination which had been optimized using the PSO algorithm could reduce the active power losses as much as $1.707 \mathrm{MW}(42.03 \%)$ and $1.887 \mathrm{MW}$ (46.47\%) respectively, being compared to the condition without any injection of the compensation (Case\#1). In addition, the implementation of the SVC compensation by using the ABC algorithm could also reduce the active power losses as much as $1.887 \mathrm{MW}(31.23 \%)$ with respect to the Case\#1. However, the implementation of the TCSC-TCPST compensation with PSO algorithm gave a slightly better result than using the capacitor bank with PSO algorithm and SVC with ABC algorithm [8].

\section{CONCLUSION}

The Particle Swarm Optimization (PSO) algorithm has been explored to determine the optimum location and sizing of capacitor banks and TCPST-TCSC combination with the aim to improve the voltage profile and to reduce the power losses of the system. It has been proven that the algorithm performed well and required small iterations number, i.e. 5-14 iterations, in determining the optimum values. The 30-bus system IEEE standard was tested to show the performance of the PSO algorithm. The optimum placement and sizing of capacitor bank and TCPST-TCSC combination on the transmission lines using the PSO algorithm have been proven to be able to improve the bus voltage bus values within the allowable voltage limits. The result also showed that the implementation of optimum TCPST-TCSC placement was more effective than the optimum placement of capacitor banks in reducing power losses of the system, giving a reduction of $46.47 \%$ and $42.03 \%$ using TCPST-TCSC combination and capacitor bank respectively. The performance of PSO algorithm also have been compared with the ABC algorithm. The implementation of the TCSC-TCPST compensation with PSO algorithm gave a slightly better result than using the capacitor bank with PSO algorithm and SVC with the ABC algorithm.

\section{ACKNOWLEDGEMENTS}

We are grateful to the Institute of Research and Community Service of Brawijaya University for the funding of the research the results of which are presented in this publication and for the Power System Engineering and Energy Management Research Group (PseeMRG), Faculty of Engineering, Brawijaya University, for the funding of this publication.

\section{REFERENCES}

[1] V. H. M. Quezada, J. R. Abbad, and T. G. S. Román, “Assessment of Energy Distribution Losses for Increasing Penetration of Distributed Generation”, IEEE Transactions on Power Systems, Vol. 21, No. 2, pp. 533-540, May 2006.

[2] H. Suyono, and R.N. Hasanah, "Analysis of Power Losses due to Distributed Generation Increase on Distribution System”, Jurnal Teknologi, Vol. 78, No. 6-3, pp. 23-28, 2016

[3] K. Padlyar, "FACTS Controllers in Power Transmission and Distribution", New Age International Publishers, New Delhi, 2007.

[4] IEEE FACTS Working Group 15.05.15, "FACTS Application”, December 1995.

[5] F. Yang and Z. Li, "Improve Distribution System Energy Efficiency with Coordinated Reactive Power Control", IEEE Transactions on Power Systems, Vol. 31, Issue. 4, pp. 2518 - 2525, 2016.

[6] M. Noroozian, L. Angquist, M. Ghandhari, G. Andersson, "Improving Power System Dynamics by SeriesConnected FACTS Devices,” IEEE Transactions on Power Delivery, Vol. 12, Issue 4, pp. 1635-1641, 1997

[7] S. Mukhopadhyay, D. Maiti, A. Banerji, S. K. Biswas, N. K. Deb, "A New Harmonic Reduced Three-Phase Thyristor-Controlled Reactor for Static VAr Compensators," IEEE Transactions on Industrial Electronics, Vol. 64, Issue: 9, pp. $6898-6907,2017$ 
[8] H. Suyono, R.N. Hasanah, and K.N. Astuti, "Optimisation of The Reactive Power Injection to Control Voltage Profile by Using Artificial Bee Colony Algorithm," Proc. of the 2016 Int. Seminar on Sensors, Instrumentation, Measurement and Metrology, pp. 18-23, DOI: 10.1109/ISSIMM.2016.7803714, 2016

[9] H. Suyono, R.N. Hasanah, E.P. Widyananda, "Power System Optimization of Static VAR Compensator using Novel Global Harmony Search Method", Accepted to be published in the International Journal of Electrical and Electronic Engineering \& Telecommunications (IJEETC), 2019

[10] N. Johansson, L. Angquist, H.P. Nee, "An Adaptive Controller for Power System Stability Improvement and Power Flow Control by Means of a Thyristor Switched Series Capacitor (TSSC)", IEEE Transactions on Power Systems, Vol. 25, Issue: 1, pp. 381-391, 2010

[11] Y. Cui, Y. Yu, Z. Yang, "Application Effect Evaluation of Demonstration Project of Thyristor-Controlled Phase Shifting Transformer in 500kV Grid", 2015 5th International Conference on Electric Utility Deregulation and Restructuring and Power Technologies (DRPT); pp. 1643-1647, 2015

[12] M.A. Sayed and T. Takeshita, "All Nodes Voltage Regulation and Line Loss Minimization in Loop Distribution Systems Using UPFC”, IEEE Transactions on Power Electronics, Vol. 26, Issue: 6, pp. 1694-1703, 2011

[13] H. Suyono, L.M. Hayusman, M. Dhofir, "Improvement of Voltage Sag Mitigation using Dynamic Voltage Restorer (DVR)”, ARPN Journal of Engineering and Applied Sciences, Vol.10, Issue 19, pp. 8684-8691, October 2015.

[14] E. Acha, FACTS Modelling and Simulation Power System, England: Wiley \& Sons, 2004.

[15] A. Keane, et.al, "Evaluation of Advanced Operation and Control of Distributed Wind Farms to Support Efficiency and Reliability", IEEE Transaction on Sustainable Energy, Vol. 3, No. 4, pp. 735-742, 2012

[16] H. Suyono, Wijono, R.N. Hasanah, S. Dhuha, "Power Distribution System Reliability Improvement due to Injection of Distributed Generation", 2017 10th International Conference on Electrical and Electronics Engineering (ELECO), pp. 1485-1490, 2017

[17] A.M. Azmy, and I. Erlich, "Impact of Distributed Generation on the Stability of Electrical Power System", IEEE Power Engineering Society General Meeting, pp. 2:1056-1063, 2005.

[18] H. Suyono and M. Zainuddin, "Injection Impact of Photovoltaic Distributed Generations (PVDG) on Power Distribution System Stability", Applied Mechanics and Materials. Vol, 785, pp. 403-408, 2015.

[19] S. Gerbex, R. Cherkaoui, A.J. Germond, "Optimal Location of Multi-Type FACTS Devices in a Power System by Means of Genetic Algorithms", IEEE Transactions on Power Systems, Vol. 16, Issue. 3, pp. 537-544, 2001.

[20] Y. Malachi and Singer, S., "A Genetic Algorithm for the Corrective Control of Voltage and Reactive Power", IEEE Transactions on Power Systems, Vol. 21, Issue: 1, pp. 295-300, 2006.

[21] M.I. Azim and Rahman M.F., "Genetic Algorithm Based Reactive Power Management by SVC”, International Journal of Electrical and Computer Engineering (IJECE), Vol. 4, No. 2, pp. 2041- 2047, April 2014.

[22] A. Bolaji and Khader, A., "Artificial Bee Colony Algorithm, Its VARiants and Application: a Survey", Journal of Theoritical and Applied Information Technology, Vol 7, No 2, 2013

[23] Y.L. Chen \& Y.L. Ke,” Multi-Objective VAR Planning for Large-Scale Power Systems Using Projection Based Two Layer Simulated Annealing Algorithms", IEE Proceeding of Generation, Transmission and Distribution, Vol. 151, No. 4, pp. 555-560, 2004.

[24] B. Venkatesh and R. Ranjan, "Fuzzy EP Algorithm and Dynamic Data Structure for Optimal Capacitor Allocation in Radial Distribution Systems", IEE Proceedings - Generation, Transmission and Distribution, Vol. 153, Issue 1, pp. 80-88, 2006.

[25] V. Z. Manusov, P. V. Matrenin, E. S. Tretiakova, "Implementation of Population Algorithms to Minimize Power Losses and Cable Cross-Section in Power Supply System", International Journal of Electrical and Computer Engineering (IJECE), Vol 6, No 6, pp. 2955-2961, December 2016

[26] M.N. Dazahra, et al., "Optimal Location of SVC using Particle Swarm Optimization and Voltage Stability Indexes", International Journal of Electrical and Computer Engineering (IJECE), Vol. 6, No. 6, pp. 2581-2588, December 2016.

[27] G. Glanzmann \& G. Andersson, "Coordinated Control of FACTS Devices Base on Optimal Power Flow", Proceedings of the 37th Annual North American Power Symposium, 2005, pp. 41-148, 2005.

[28] L. J. Cai, I. Erlich, G. Stamtsis, "Optimal Choice and Allocation of FACTS Devices in Deregulated Electricity Market Using Genetic Algorithms”, IEEE PES Power Systems Conference and Exposition, 2004, Vol.1, pp. 201207, 2004. 